This item was submitted to Loughborough's Research Repository by the author.

Items in Figshare are protected by copyright, with all rights reserved, unless otherwise indicated.

\title{
Gradient colour deviation in woven textiles to correspond to pictorial images in diversity
}

PLEASE CITE THE PUBLISHED VERSION

http://dx.doi.org/10.1080/17543266.2015.1116615

\section{PUBLISHER}

Taylor \& Francis (C) The Textile Institute and Informa UK Ltd.

\section{VERSION}

AM (Accepted Manuscript)

\section{PUBLISHER STATEMENT}

This work is made available according to the conditions of the Creative Commons Attribution-NonCommercialNoDerivatives 4.0 International (CC BY-NC-ND 4.0) licence. Full details of this licence are available at: https://creativecommons.org/licenses/by-nc-nd/4.0/

\section{LICENCE}

CC BY-NC-ND 4.0

\section{REPOSITORY RECORD}

Kim, Ken Ri, Frankie Man Ching Ng, Jiu Zhou, and Jinlian Hu. 2019. "Gradient Colour Deviation in Woven Textiles to Correspond to Pictorial Images in Diversity”. figshare. https://hdl.handle.net/2134/24736. 


\title{
Gradient colour deviation in woven textiles to correspond to pictorial images in diversity
}

\author{
Ken Ri Kim*, Frankie Ng, Jiu Zhou and Jinlian Hu \\ Institute of Textiles \& Clothing, The Hong Kong Polytechnic University, Kowloon, Hong Kong
}

This study aims to propose optimal weaving conditions for creation of natural shading effect in woven textiles. By applying the weave structure and pattern theories, the two core parts of weaving are explored and examined towards improving realisation of gradient weave colours. When planning experiments, weave repeat sizes from 12- to 30-thread are created into a shaded weave series and compounded in multi-weft figuring method. In terms of weave pattern, a colour spectrum image is designed and its split primary colour layers (e.g. cyan, magenta, yellow and black) are employed as weave pattern. In conjunction with varied weaving conditions, a colour spectrum image is reproduced in 19 different woven forms. In this study, comparative analysis is approached based on the samples resulted from trials and the practical research is explained in details of weave structure and weave pattern specifications to propose the core principle of establishing gradient colour deviation.

Keyword: woven textiles, natural shading, digital weave pattern, shaded weave series

\section{Introduction}

The capability to generate natural shading effect is critical to correspond to woven textiles in diversity. In employment of basic satin and twill, discontinuous thread floats are generated within a repeat while the substrates of respective images is defined by greyscales and aligned 
with the weave structure layout (Randall, 2004; Watson \& Grosicki, 1975). Inspired by the shaded weave structure theory and multi-weft figuring method, practical experimentation is designed to propose an optimal weaving conditions for smooth colour deviation (Zhou, 2011). In weave structure design, either satin or twill is developed into shaded weave series in which varied thread lengths are generated to represent the colours of an artwork (Watson \& Grosicki, 1977). Regarding structural weave balance and weave colour display, to create two different shaded weave series in an identical repeat are suggested and encouraged (Zhou, 2011). When building the first weave series, each pick line of a weave repeat receive one stitching point yet, it is transformed each time by adding interweaving points on a regular basis. While the second series is built in same principle, it takes different transition direction, step movement and starting point to the first series ( $\mathrm{Ng} \& \mathrm{Zhou}, 2010)$. Figure 1 shows one of the examples of paired shaded weave series created in 12-thread.

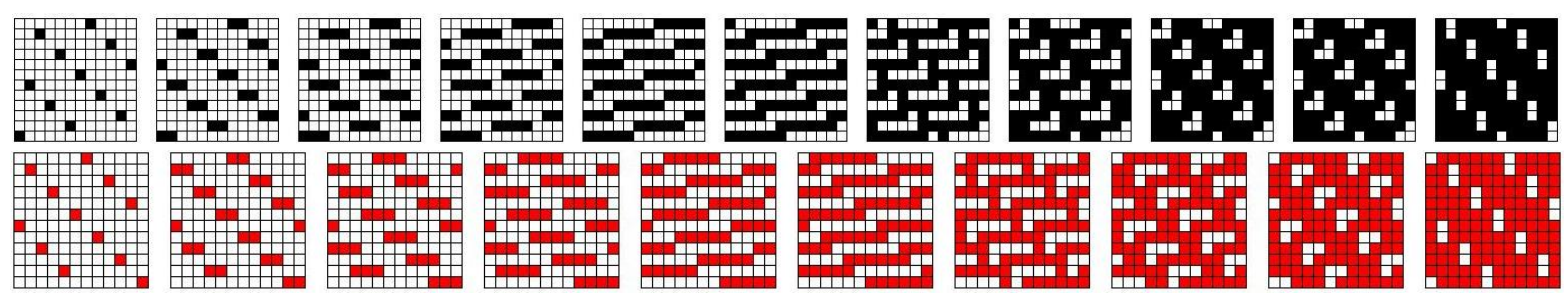

Figure 1. An example of first and second shaded weave series in 12-thread (Zhou, 2011)

When an image is either designed or selected for fabrication, it is separated into its primary colour layers (e.g. cyan, magenta, yellow and black). Once they are employed as weave patterns, the greyscale in a layer symbolise the pigment densities required for reproduction. In this study, based on the weave structure and pattern theories, varied weaving applications are explored towards improving realisation of shaded weave colours and the practical research is explained with weave structure and pattern details. 


\section{Method}

Weave sizes which are capable of maintaining a proper firmness and tightness are hired and developed into shaded weave series. Based on the weave structure development, weave patterns are generated on the basis of the subtractive primary classification. Both weave structure and pattern are combined and mutually interacted for fabrication. The experimentation result is presented with weaving specifications such as sample image, weave size, weave variety, colour state, increasing interlacement value, and the first weave of a first and second series. The weave colour status is assessed through analytical comparison and classified three different measurement scales from 'Poor', 'Satisfactory' to 'Outstanding'.

\subsection{Experimental image for inspection of varied weaving specification}

A proper artwork selection is crucial to experiment with varied weaving specifications. The colours of an image are in a seamless colour deviation and the colour gamut is required to lay in subtractive mixing principle as weave patterns are designed by the primary group. In printing, hue alteration is occurred by the amount of pigment while in woven fabrication, the delicate exhibition of individual yarn colour is the way to achieve and generate projected colours (Dawson, 2002). Regarding all critical conditions, the colour spectrum image is designed and created for practical experimentation (Figure 2).

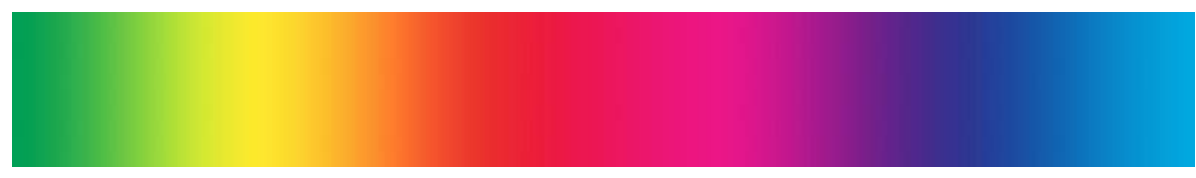

Figure 2. Reproduction of a colour spectrum image via Jacquard weaving

For convenience purpose, the spectrum colours are categorised into green, yellow, red, magenta, blue and cyan. In fabrication, weave patterns play an important role to locate thread 
floats in associated regions and all regions should receive an exact amount of thread colour exhibition to present the indiscernible deviation. In addition, the colour-changing regions are designed to establish their colourway by a pair of filling yarn juxtaposition (e.g., $[\mathrm{C}]+[\mathrm{M}]=$ blue, $[\mathrm{C}]+[\mathrm{Y}]=$ green and $[\mathrm{M}]+[\mathrm{Y}]=$ red).

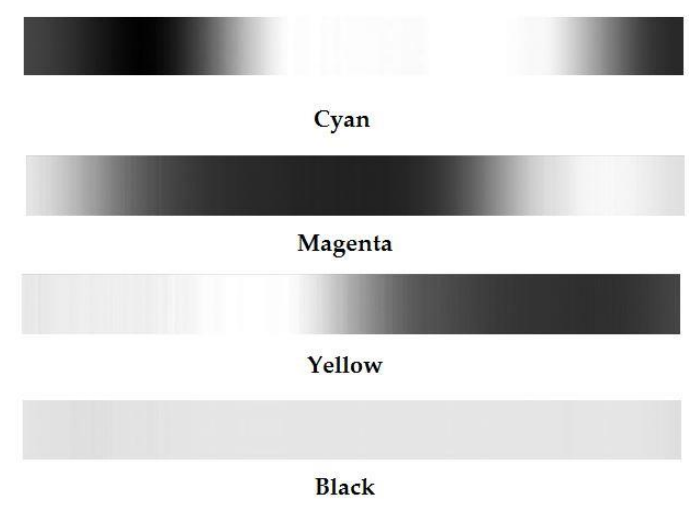

Figure 3. Spectrum image split into CMYK colour classification

Once a colour spectrum image is split into its primary colour layers, their features are turned in grey-scales. As the eight-bit mode can display the monochromatic images in an acceptable quality (Kendra, 2004), the four grey images is presented with $2^{8}(256)$ greyscale levels (Figure 3). However, the greyscale range in each split layer is reduced to match with the total number of the selected shaded weave verity to make one-to-one correspondence for recreation (Ng \& Zhou, 2009).

\subsection{Accessible weave repeat sizes for experimentation}

Filling yarn lengths floated on the fabric surface depend on a weave repeat size. In use of Computer-aided design system (CAD), when weave structures are corresponded to weave patterns, resultant weave colour effects can be simulated and visualised (Aldrich, 1994). When shaded weave series are too large and each pick line receive deficient interweaving 
points, fillings in pick lines are insecure and fabric looseness is occurred via long floats. Therefore, before building the shaded weave database, preliminary trials are conducted to determine a feasible scope of weave repeats as the examination of fabric tightness and structural balance is only possible by producing actual samples.

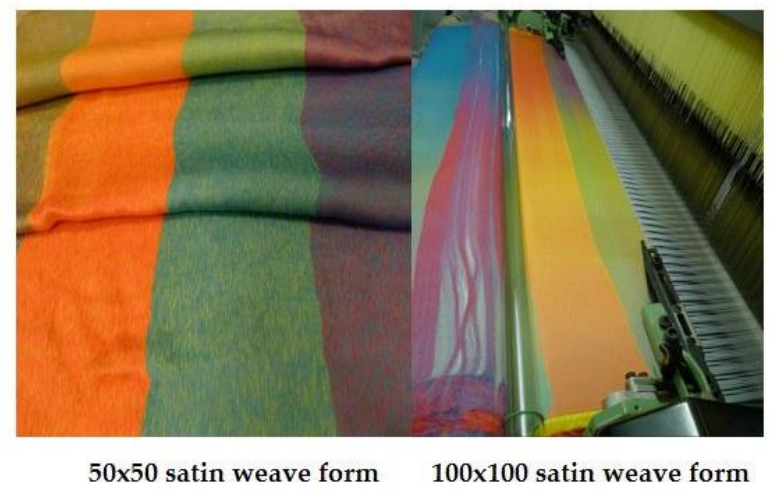

Figure 4. Preliminary experimentations on 50- and 100-thread weaves

Primarily, 50-thread and 100-thread weaves are investigated to testify their practicalities for shaded weave series development. The experimental result (Figure 4) shows that the consequential fabrics shaped in two sizes turn out to be too loose to be wearable or functional. Therefore, the feasible scope of weave repeat stayed within 30-thread and 19 different weave repeats from 12- to 30 -thread weave size are employed to create shaded weave series for experimentation.

\subsection{Weaving specifications for colour spectrum recreation}

A full comprehension of the theories and practical approaches are obliged for such fabrication. A pair of shaded weave series is built in each size by giving an opposite transition direction and different starting points and step movements for even distribution of filling yarns. From 12- to 30-thread, the shaded weave sets are built with a different number of interlacement 
increase and therefore, an accessible weave varieties varies with each series (Table 1). However, the total number of accessible weave variety ( $T$ ) is estimated by Equation (1) as a total number of interlacing points is gradually occupied when a regular number of interlacement enhancement $(\mathrm{E})$ is applied to a weave repeat $(\mathrm{W})(\mathrm{Ng}, \mathrm{Kim}, \mathrm{Hu} \& \mathrm{Zhou}$, 2014).

Table 1. Varieties of shaded weave structure series ( $\mathrm{W}=$ weave repeat, $\mathrm{E}=$ interlacement enhancement and $\mathrm{T}=$ total weave variety)

\begin{tabular}{|c|c|c|c|c|c|}
\hline $\mathbf{W}$ & $\mathbf{E}$ & $\mathbf{T}$ & $\mathbf{W}$ & $\mathbf{E}$ & $\mathbf{T}$ \\
\hline $\mathbf{1 2}$ & 3 & 41 & $\mathbf{2 2}$ & 11 & 41 \\
\hline $\mathbf{1 3}$ & 13 & 12 & $\mathbf{2 3}$ & 23 & 22 \\
\hline $\mathbf{1 4}$ & 7 & 25 & $\mathbf{2 4}$ & 6 & 89 \\
\hline $\mathbf{1 5}$ & 5 & 40 & $\mathbf{2 5}$ & 5 & 116 \\
\hline $\mathbf{1 6}$ & 4 & 57 & $\mathbf{2 6}$ & 13 & 49 \\
\hline $\mathbf{1 7}$ & 17 & 16 & $\mathbf{2 7}$ & 9 & 73 \\
\hline $\mathbf{1 8}$ & 6 & 49 & $\mathbf{2 8}$ & 7 & 106 \\
\hline $\mathbf{1 9}$ & 19 & 18 & $\mathbf{2 9}$ & 29 & 28 \\
\hline $\mathbf{2 0}$ & 5 & 73 & $\mathbf{3 0}$ & 6 & 141 \\
\hline $\mathbf{2 1}$ & 7 & 58 & - & - & - \\
\hline
\end{tabular}

$$
T=\left(W^{2}-W\right) \div E-\{(W \div E)-1\}
$$

Table 2. Technical setting for a colour spectrum reproduction

\begin{tabular}{|c|c|c|}
\hline Composition & Weft & Warp \\
\hline Material & $100 \%$ polyester & $100 \%$ polyester \\
\hline Thread colour & Cyan/magenta /yellow/black & Off-white \\
\hline Yarn count & 50 denier & 100 denier \\
\hline $\begin{array}{c}\text { 4 colour filling } \\
\text { density }\end{array}$ & 944 picks $/ 10 \mathrm{~cm}$ & 472 ends/10cm \\
\hline Jacquard machine 30 -thread & Stäubli JC6 \\
\hline Pattern repeat & $173 \mathrm{~cm}$ (width) $28.22 \mathrm{~cm}$ (height) \\
\hline Weave repeat & From 12 to $30-$ thread \\
\hline Shaded weave variety & \multicolumn{2}{|c|}{ From 12 to 141} \\
\hline Software applied & Photoshop CS/Arahne CAD \\
\hline
\end{tabular}

When the four split colour layers (Figure 3) are aligned with a shaded weave series, each greyscale level in a layer is used as a standard to select a proper shaded weave in a series. The first set of a weave repeat corresponds to odd numbers of weave layers (i.e. cyan and yellow) 
and the second series is for even layers (i.e. magenta and black). In multi-weft figuring method, the four colour layers are all combined and integrated for production. The experimentations are conducted with the aid of the Arahne Jacquard CAD programmes, Slovenian products, Stäubli JC6 weaving machine, and a Photoshop programme. The investigation parameters are detailed in Table 2.

\section{Experiment Result: correlation between weave structures and weave patterns}

\subsection{Colour spectrum fabrics of 12-, 16-, 24- and 26-thread}

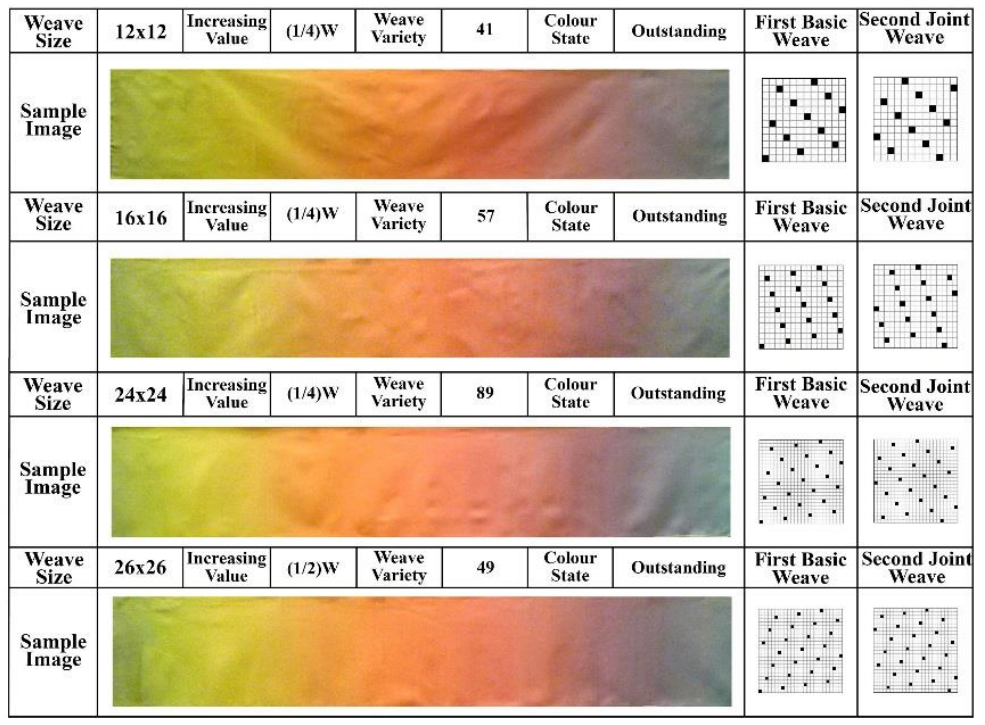

Figure 5. Spectrum fabrics of 12-, 16-, 24- and 26-thread

The fabric samples of 12-, 16-, 24- and 26-thread (Figure 5) are selected to illustrate successful interactions between weave structure and pattern as they are produced in seamless colour visitation without any colour streak lines. Their shaded weave varieties are ranged from 41 to 89 and the interlacement is increased either $(1 / 2) \mathrm{W}$ or $(1 / 4) \mathrm{W}$ when they are transferred to another derivatives. Regarding weave repeat size, variety and weave pattern conditions, the weaving applications are found to be optimal to establish seamless colour deviation. In the 8-bit mode, the four split layers are presented within 256 different levels yet, 
reduction is applied to each layer to associate with the shaded weave variety.
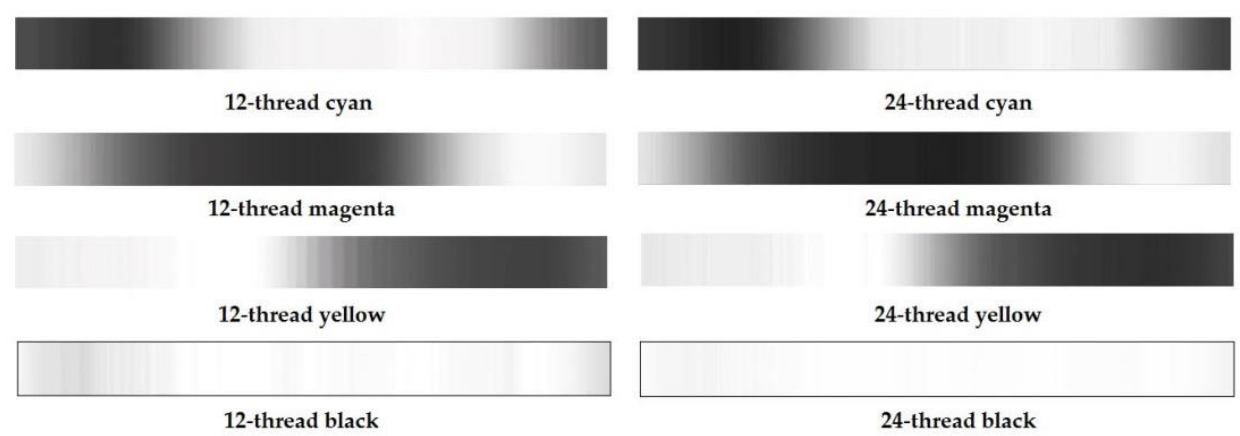

Figure 6. Weave patterns of 12- and 24-thread

The greyscale reduction may lead the colour streak lines where greyscale values drop and unify with other values. As regards the state of each sample, the weave patterns comprised of 41 to 89 greyscale ranges are proficient to embrace and present a wide selection of greyscales within the limit. In contrast, since the sample produced by the 24-thread is more with weave varieties and greyscales, wider colour gamut and evener shading effect are expected in 24thread fabrication (Figure 6). However, no momentous difference is found when compared with the 12-thread fabric sample.

\subsection{Colour spectrum fabrics of 25-, 28- and 30-thread}

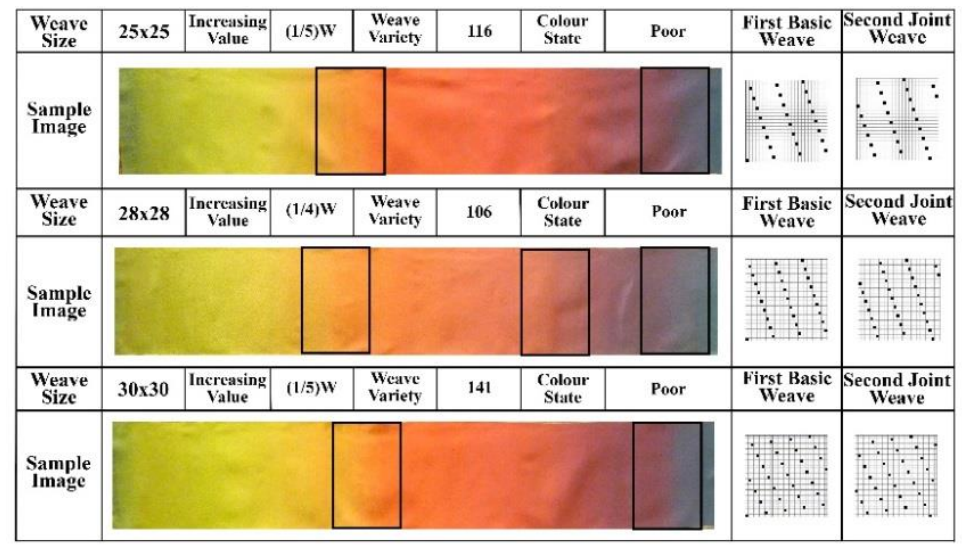

Figure 7. Spectrum fabrics of 25-, 28- and 30-thread 
Smoother colour deviations are expected when the fabrics are produced with a large number of shaded weave varieties. In this condition, a small number of greyscale reduction is applied and thus, more weave colours are expected to emerge through the interaction between weave structures and greyscales. However, in review of 25-, 28- and 30-thread cases, their gradual colour deviation status revealed as unsatisfactory although their shaded weave series are comprised of over a hundred variety (Figure 7). As the corresponded weave repeats are oversized regarding an artwork scale, filling floats become relatively long and the associated regions are not large enough to embrace all the particulars. Therefore, the regions where colours are deviated become condensed and the colour exhibitions look disorderly.

\subsection{Colour spectrum fabrics of 20-, 22- and 27-thread}

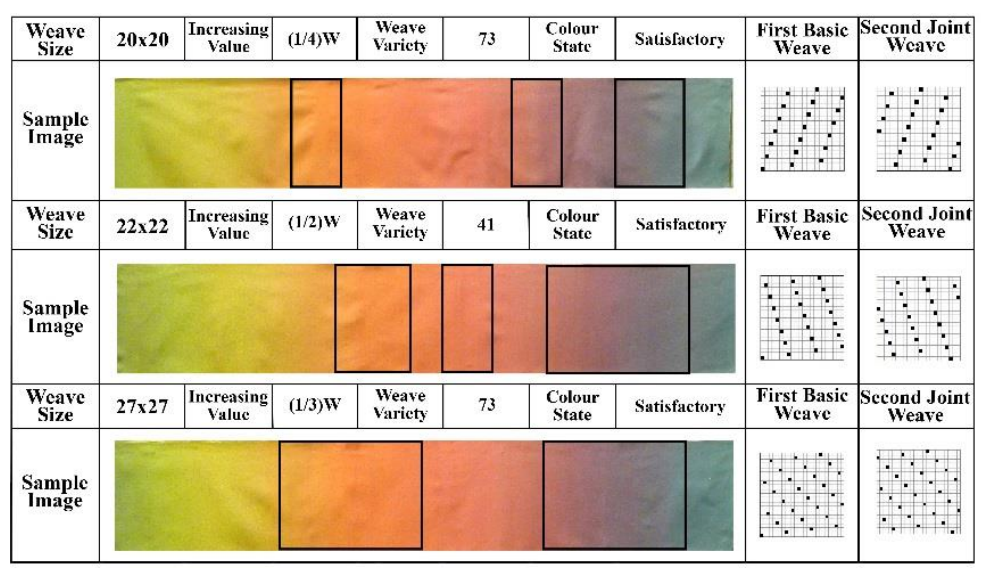

Figure 8. The spectrum fabrics of 20-, 22- and 27-thread

The 20- 22- and 27-thread fabrication are defined as satisfactory (Figure 8). Colour streak lines are not obviously appeared yet, the colour changing regions are formed faintly uneasy. When shade weave series is built in relatively large repeat sizes, weave colour presentation is perceptively influenced by the applied number of weave variety. 20- and 27-thread weaves are stayed less than a hundred yet, the applied varieties exceed its receptive capability to 
adopt all variance. On the other hand, in the 22-thread production, comparatively, a small number of shaded levels are applied to weave pattern yet, the colour statue is faintly unstable with its floats.

\subsection{Colour spectrum fabrics of 13-, 19-, 23-, 29-thread}

The 13-, 19-, 23- and 29-thread fabric are considered ineffective as streak lines are all appeared on the surface of the fabrics (Figure 9). In building a weave repeat into series, single weaves are radically transformed as an interweaving point is added to each pick line whenever they are altered to another weave structure form. In this circumstance, the filling yarns are floated in a drastic change within a small number of shaded weave variety.

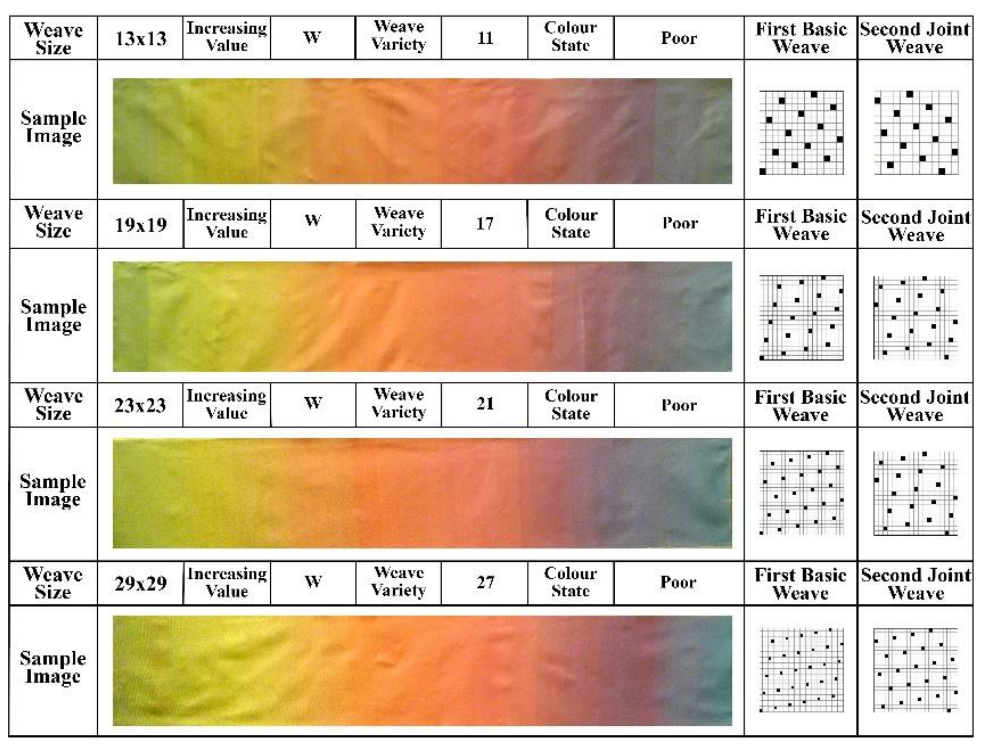

Figure 9. Spectrum fabrics of 13-, 19-, 23- and 29-thread

In addition, if greyscale reduction is operated in a large scale, the integration of the values is processed with large tolerance (Kendra, 2004) in which discontinuous tones of greyscales are resulted from the procedure. For example, when the 13-thread shaded weave series is aligned with weave patterns, 256 greyscales is unified and represented with only 12 levels (Figure 
10). As a result, undesirable colour streaks are unavoidable through the excessive unification. Therefore, when building shaded weave series, a number of weave variety should be considered in conjunction with the interlacement enhancement so as to maintain an adequate number of greyscales and to generate gradual alternations in float lengths.

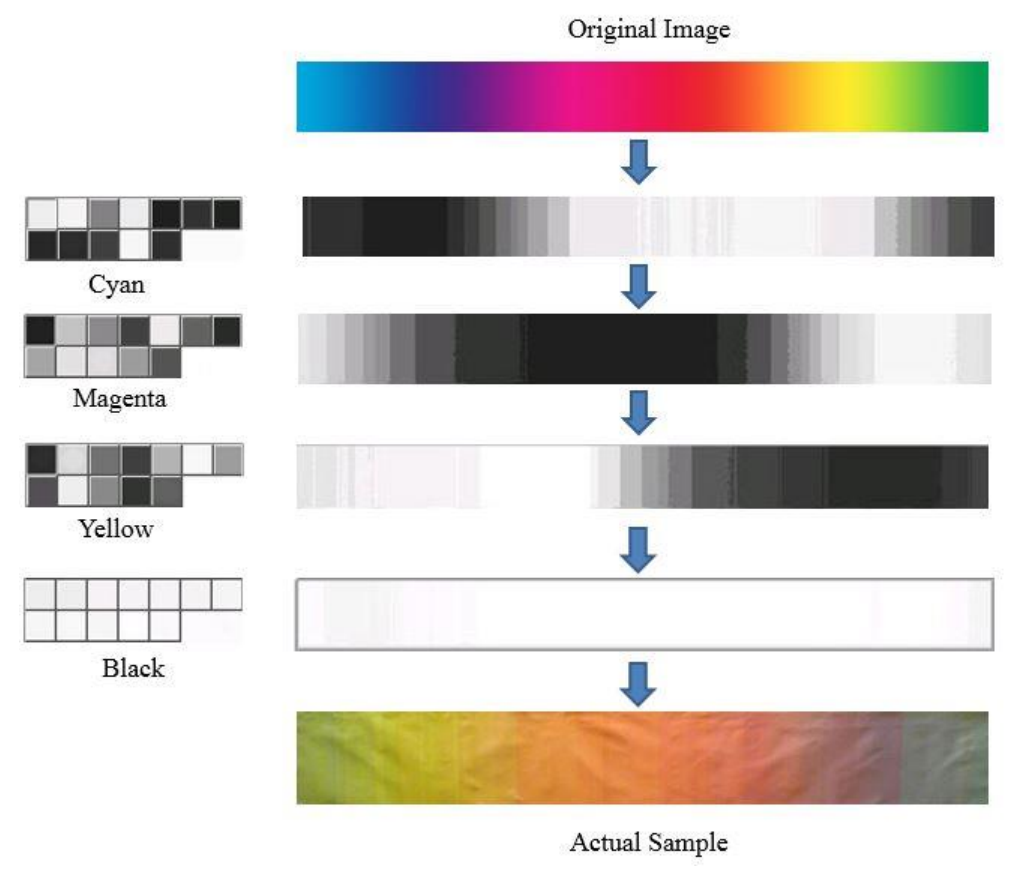

Figure 10. Spectrum fabric of 13-thread in multi-weft figuring method

\subsection{Texture and angle of cloth surface}

The angle formed on fabric depends on: (a) the comparative proportion of ends and picks in a unit space; and (b) the ratio of growth of one interlacing to another (Watson \& Grosicki, 1975). The texture of fabrics are formed with a regular transverse lines on the surface as basic form of satin and twill are transformed by adding interlacements in the centre of its first intersecting point. In shaded weave series development, interweaving points are found through a regular step movement and the single shaded weaves are compounded in multiweft figuring method. As a result, the firstly established diagonal angle lines are appeared as fabric texture as Figure 10 shows the 24-, 28- and 29-thread samples. In case of 28-thread and 
29-thread fabrics (Figure 11), the diagonal lines of the texture are formed through the fixed interweaving points as a regular lifting are given among the first and second weave series combination. On the other hand, the 24-thread fabric has fewer angle features as their first interweaving points are dispersed in their first foundation.

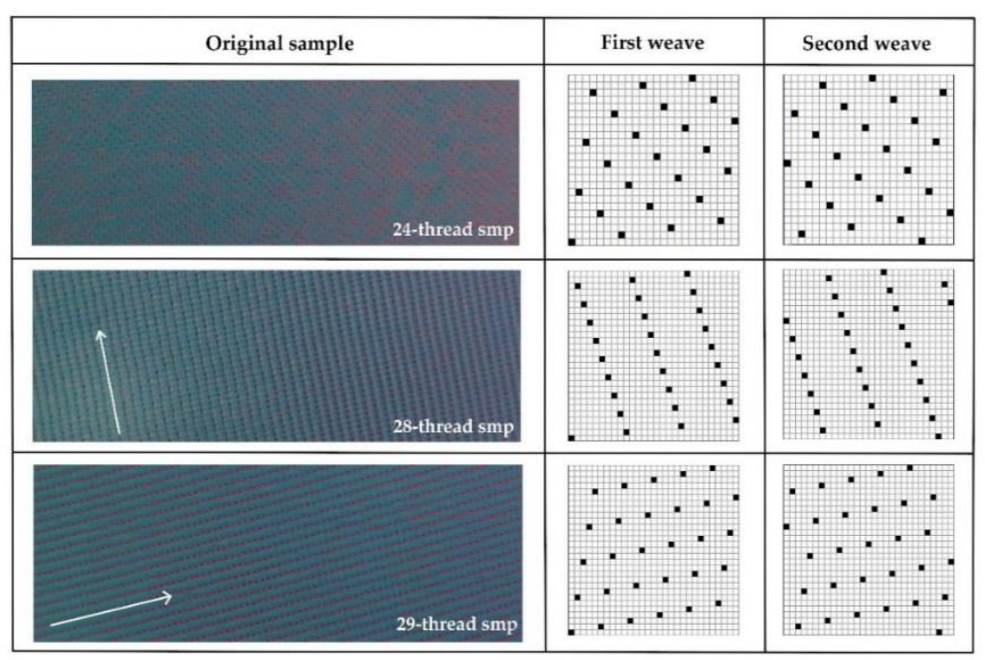

Figure 11. Relationship between weave structure and fabric texture

\section{Discussion}

In employment of a colour spectrum image, the weave structure scopes from 12- to 30-thread are created into different forms of shaded weave series and experimented in company with split four colour layers. The core relationship between weave structure and pattern are inspected for establishing gradient colour deviation. Individual 19 samples are produced and categorised in three different classifications; 'poor', 'satisfactory' and 'outstanding'. Their weaving conditions are reviewed and analysed in the aim of building reliable weaving applications.

In the case of the 13-, 19-, 23- and 29-thread fabrics (Figure 8), shaded weave series are consisted of a small number of varieties and the greyscale ranges are unified with a large 
tolerance. Therefore, the colours of woven clothes barely are maintained and established silkiness gradation. As filling floats are exhibited in a radical change with limited length variation, the weaving application is built and corresponded in short supply. The fabrics produced in 14-, 17- and 23-thread (Figure 12) are aligned with the identical insufficiencies. In fabrication, the mutual interaction between weave structure and pattern is miscarried as deficient shaded weaves and greyscales are applied to elaborate colourway reproduction.

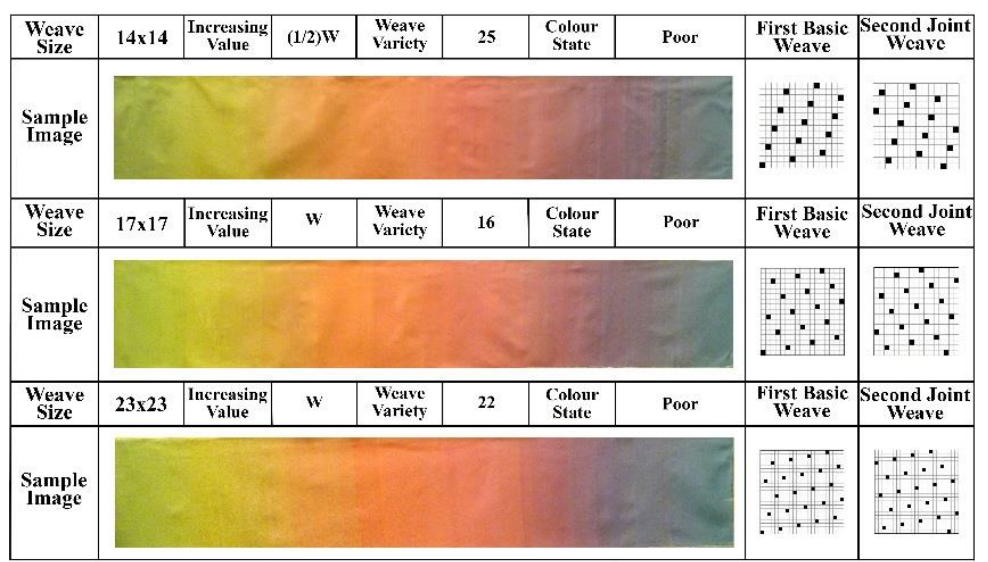

Figure 12. The spectrum image of 14-, 17- and 23-thread

When a weave repeat size is become large, filling yarn floats grow longer. In limited spaces, if the applied weave repeat is oversized regarding an artwork so that assigned colours regions are covered with excessively long floats, colour changing regions where warps and wefts are interweaved in complex manner are difficult to manange a proper portion of yarn colour exhibition. The samples of 25-, 28- and 30-thread fabrication (Figure 7) are lay in the cases and the 20-, 22- and 27-thread fabrication are also added for the important factors of a weave repeat size and its shaded weave variety regarding an artwork scale.

In addition to the fabric samples of 12-, 16-, 24- and 26-thread (Figure 5), the 15-, 18- and 21-thread fabrication (Figure 13) are well aligned and collaborated with the two core parts of 
weave structure and pattern. Each layer of weave patterns are fulfilled with a sufficient variations of filling floats and the associated colour regions are covered with a proper proportion of float lengths. Therefore, seamless deviation are established and achieved through their interaction.

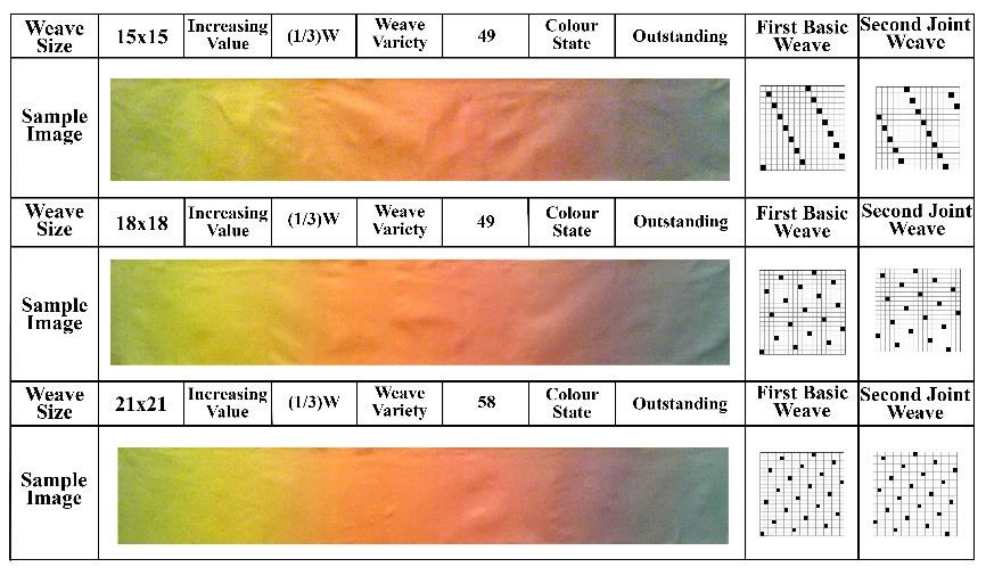

Figure 13. The spectrum image of 15-, 18- and 21-thread

In reproduction of a colour spectrum with varied weaving specifications, high-quality weave colour deviation is possible on condition that 1) the colour streak lines are avoided as greyscale reduction do not interfere with the original appearance of an image; 2) the lengths of thread floats grow progressively; 3) a proper weave repeat size and shaded weave variety is applied regarding receptive capacity of an artwork; and 4) continuous tonnes of greyscales should be maintained in weave patterns.

\section{Acknowledgement}

This project is funded by the General Research Fund of the Hong Kong Research Grant Council (project code PolyU 5274/09E) and the Hong Kong Polytechnic University (projectcode B-Q17G). 


\section{References}

Aldrich, W. (1994). CAD in clothing and textiles: A collection of expert views (2nd ed.). Oxford, Cambridge, Mass: Blackwell Scientific Publications.

Dawson, R. M. (2002). Colour and Weave Effects with Some Small Weave Repeat Sizes. Textile Research Journal, 72(10), 854-863.

Kendra, E. (2004). Colour companion for the digital artist. NJ: Pearson/Prentice Hall.

Ng, F., Kim, K.R., Hu, J., \& Zhou, J. (2014). Patterning technique for expanding colour variety of jacquard fabrics in alignment with shaded weave structures. Textile Research Journal, 84(17), 1820-1828.

Ng, M. C. F., \& Zhou, J., (2009). Innovative layered-combination mode for digital jacquard fabric design. Textile Research Journal, 79(8), 737-743.

Ng, M. C. F., \& Zhou, J. (2010). Full-colour compound structure for digital jacquard fabric design. The Journal of the Textile Institute, 101, 52-57.

Randall, D. L. (2004). Digital imaging for textiles - next generation. Retrieved May 16, 2013, from www.techexchange.com

Watson, W., \& Grosicki, Z. (1975). Watson's textile design and colour: Elementary weaves and figured fabrics [Textile design and colour] (7th ed.). London: NewnesButterworths.

Watson, W., \& Grosicki, Z. (1977). Watson's advanced textile design: Compound woven structures [Advanced textile design] (4th ed.). London; Boston: NewnesButterworths.

Zhou, J. (2011). Research and creation of printing-like effect digital jacquard fabric. Advanced Materials Research, 295-297, 2568-2571. 